\title{
EVALUATING LAW TEACHING: TOWARDS THE IMPROVEMENT OF TEACHING OR PERFORMANCE ASSESSMENT?
}

\author{
RICHARD JOHNSTONE*
}

\section{THE IMPORTANCE OF EVALUATING TEACHING}

In the last few years there has been a move towards assessing and appraising the quality of teaching in Australian universities. While some law schools have on their own initiative paid more attention to this process, in others the issue has arisen in the context of the move towards staff assessment and appraisal which developed out of the second tier National Wage negotiations in the tertiary education sector in $1988 .{ }^{1}$ Until these developments, there had been little or no attempt to scrutinise ${ }^{2}$ teaching within law schools. It has been commonly accepted that where teaching has been scrutinised for the purposes of promotion, confirmation and recruitment, scrutiny was often based on rumour, innuendo and hearsay. In this context, then, the move towards more rigorous scrutiny of teaching in law schools should be welcome.

Of course, there are arguments for and against more rigorous scrutiny of teaching. Why should teaching be ignored or paid lipservice in selection, confirmation and promotion when it is an important and time consuming component of the work of academics in law schools? If teaching is important, it should be taken seriously in recruitment and promotion. This means scrutinising it carefully and fairly. If, as seems likely, academics working in law schools in the 1990s will become much more accountable for their teaching, we had better get used to the idea of 
teaching being more rigorously scrutinised.

This, however, raises a problem of vertical equity. Why should today's new teachers have their teaching rigorously examined when in the past teaching was largely ignored and, where it was scrutinised, this was done in a far less rigorous fashion than the assessment of research? It is often argued that scrutinisation of teaching is difficult to do, and therefore should not be attempted. It is this last point that this article seeks partly to address. More particularly, this article examines why and how teaching should be scrutinised.

The purpose of the process of scrutinising teaching is often overlooked. It is the purpose of this article to suggest that there are at least three major reasons for these processes: evaluation, assessment and staff appraisal and that they should be separated, with different methods used for each.

The first and most important basis is the evaluation of teaching where the individual teacher is concerned to discover areas needing improvement so that he or she can take steps to remedy weaknesses. This process, which is primarily diagnostic, is best seen as a natural part of good teaching. It is concerned with the teacher seeking information on the effects of teaching on students' learning and ways of changing teaching to improve that learning. A second basis is the assessment of teaching performance for the purposes of staff selection, confirmation of tenure and promotion. This is a function concerned with management and seeks to ascertain whether a member of staff has achieved or is maintaining a specified standard. This process is not diagnostic, but rather focuses on rewards and punishments. ${ }^{3}$ A third basis, which will not be taken up in this article, is staff appraisal in which supervisors help teachers improve their performance. It involves regular discussions between supervisors and teachers and focuses on goal setting and plans for improvement. It is a supportive and diagnostic process, initiated by management rather than staff, but not concerned with punishment or rewards. ${ }^{4}$ There are very sound reasons for separating these three processes. Teachers should be encouraged to search out strengths and weaknesses in their teaching, to experiment with new approaches and to work cooperatively with other teachers to plan and improve courses and their teaching. Anything which inhibits these processes, such as 
critical scrutiny for the purposes of promotion or confirmation, should be avoided. ${ }^{5}$

This article, then, focuses on the first and second categories outlined above - the evaluation of teaching and the assessment of teaching - and argues that the most important process is the evaluation of teaching. ${ }^{6}$

For the purposes of this article, teaching has a wider meaning than interaction with students in the classroom. It includes courserelated interaction with students outside the classroom, the structure and content of courses, providing feedback on the performance of students, the method of assessment, course materials and the ability to work with colleagues as a team when preparing, conducting and evaluating courses. These different aspects of teaching are inextricably linked and cannot be separated in the evaluation or assessment of teaching.

\section{THE USE OF DIAGNOSTIC INFORMATION OR}

\section{FEEDBACK TO IMPROVE TEACHING}

The evaluation of teaching is the responsibility not of management, but of the teacher. Good teaching involves continuous monitoring of the teacher's own work and its impact on student learning. Most law teachers have never seen themselves teach nor asked colleagues to sit in on their classes to offer constructive feedback on ways to improve their teaching. At best, they have been given feedback by their students. Yet we need to know how we perform in class. We need support and advice from colleagues in order to identify our strengths and weaknesses, to learn how to make the most of our strengths and to improve upon our weaknesses. We may need to have a clearer idea of the importance of teaching objectives: what our teaching objectives should be and how we can achieve them. We may need to learn new teaching methods such as the use of small groups, brainstorming, mooting and role plays in class. We may also need to learn new teaching techniques, particularly how to use questions

effectively, and we may need to learn how to use new devices such as reading guides, printed materials, overhead projectors, chalk boards, white boards, videos, computers and so on, in order better to achieve our objectives. We may need to broaden the perspectives 
of our courses, by introducing theoretical and interdisciplinary themes into our classes or may need to restructure areas of the course which do not serve their intended purposes. We may need to reconsider our forms of assessment so that we can accurately assess whether students are meeting learning objectives or provide better feedback on their performance during the course so that students can chart their progress. We may need to be more aware of gender, class or multicultural issues and their impact on course content, teaching and interactions with students both inside and outside the classroom. ${ }^{7}$ We may need to acquire, or improve, counselling skills for dealing with students outside the classroom. The overriding criterion for the evaluation of teaching is whether the teaching enhances learning by students.

North American research indicates that most teachers do not view their teaching in the same way that their students or their colleagues view it. ${ }^{8}$ It is important, therefore, to get a variety of views of our teaching. There are a number of ways of getting this sort of diagnostic information or feedback about teaching performance. Each provides only a partial perspective so it is important to use more than one method of evaluation. The different methods of obtaining feedback are set out below.

\section{Student Feedback}

An important source of feedback is the students who are being taught in the course. An obvious source of information about the course and its teaching is students' responses to the work they have been set. Again, the crucial question is whether their understanding of the discipline and their level of skills have been enhanced. The effectiveness of the course and of its teaching can be evaluated by looking at the level of enthusiasm during class, the manner in which students approach learning during the course and the insights and misconceptions apparent from the assessment performed by students during the course. Some indication can also be gained from the number of enrolments and withdrawals although this sort of information must be treated very carefully.

Student evaluation is a useful source of information about our teaching. Students see more teaching than anyone else and they are best able to indicate how effectively the course and its teaching are assisting them to understand a particular subject or to develop 
relevant skills, interests or values. Student feedback is, therefore, probably the best single source of information about whether or not a teacher is enhancing the learning of students. ${ }^{9}$ There is also evidence that student evaluation can greatly benefit some teachers. ${ }^{10}$ Student evaluation is, however, a far from perfect mode of feedback. As we all know from personal experience, many students have a very primitive view of legal education and tend to evaluate our courses and our teaching by those standards. Students are unlikely to be able to comment on the professional relevance or the quality of the academic content of the course. To some students, the good teachers are often those that "spoon feed" simplified material in a clear and concise manner that facilitates note-taking and enables the student to avoid reading any material before or after class. Even better, if the teacher is amusing or, strangely, authoritarian. Yet from an educational perspective we would probably all accept that these, apart perhaps from the capacity to be amusing, are not the criteria of good teaching. Good teaching involves the student taking responsibility for her or his learning, with the teacher seeking to stimulate, guide, inspire and challenge student learning, not just to pass knowledge on to rapidly scrawling students. Good teaching invariably involves attitudes and activities which encourage high quality learning. It involves being comfortable with the subject and being enthusiastic about sharing a love of the subject with others. It requires clear explanations, but more importantly implies making the material of the subject genuinely interesting, so that students find it a pleasure to learn it. It also involves showing concern and respect for students, being available to them and giving high quality feedback on their work. Good teaching seeks evidence of understanding the effects of teaching on students. It uses a variety of techniques for assessment which avoid requiring students to learn by rote or merely reproduce detail. It also involves an application of flexible methods more effective than a diet of straight lectures and tutorials. Good teaching methods should demand student activity, problem solving and cooperative learning. Good teaching also involves working at the students' level, making clear what has to be understood, and why, and encouraging student independence. ${ }^{11}$

It is largely our fault if students use primitive criteria in the evaluation of our teaching because we very rarely discuss with our 
classes issues of legal education. An essential part of good law teaching, therefore, should be the communication to students of the learning objectives in each course, ${ }^{12}$ the reasons for those objectives, a discussion of the style and method of teaching to be used $^{13}$ and the reasons for the adoption of those styles or methods. ${ }^{14}$ This enables students to give useful feedback about teaching, because criteria of performance have been articulated at the outset of the course.

The use of regular student evaluation forms, distributed by the teacher to students during the course, is one of the methods of getting useful student feedback. It is very important to know how our students respond to our teaching: are we getting through to them; are they learning anything; are they enjoying the classes; are the teaching materials stimulating and challenging; does the course need improvement; is the assessment appropriate; is the workload too heavy or too light; are students working for our classes? We also need to discuss with our students the issues raised by the feedback and to explore the underlying reasons for any problems that may be raised to find acceptable ways of dealing with these issues. For this form of feedback to be useful, it needs to be sought during the course, so that remedial steps can be discussed with the class and implemented during that course, not later when there is no chance to develop new approaches with the same students.

To get the most out of this form of student feedback, the feedback forms filled in by students should be confidential to the teacher and should not be used by the teacher for the purposes of staff selection, promotion or confirmation of tenure. ${ }^{15}$ The purpose should be to develop an honest and constructive interaction between teacher and students and, if it is to be most effective, this should be confidential.

The forms should also enable students to make comments about all aspects of the course, both good and bad, and should be aimed at ascertaining how students are finding the teaching of the course, what their assumptions are about the course and about legal education in general, and whether, and how, they are working for the course. The emphasis should be on qualitative comments about teaching, and these are best elicited by a series of broad open-ended questions which allow students to say what they think about classes without having their comments overly constrained. Students should 
only be asked to comment on matters that they are in a position to answer and care should be taken to ensure that the questionnaire does indeed address student concerns, including gender and multicultural issues pertaining both to the course and the method of teaching. Some form of student evaluation should occur after all the course assessment has been completed so that students can comment on the appropriateness of the assessment process. Questionnaires should be short, leaving plenty of space for student comments and should be issued and collected during the same class, to ensure a high response rate. There is little of value to be gained from feedback forms which ask students to rank performance quantitatively by reference to numbers or categories such as poor, average, good, excellent or similar categories. The information gained from these forms is virtually useless because even if problem areas are identified, students are usually given very little scope to explore the underlying reasons. Results which have numbers attached to them have no special validity and tend to obscure the fact that the numbers are generated from the subjective opinions of students with little guarantee of consistency attached to the values attributed to the numbers. ${ }^{16}$

Questionnaires should also avoid asking students to compare one teacher with another or whether the student would want to take another course taught by the same teacher. Comparative ratings of any kind, whether they be about teaching quality or course preferences, are not usually relevant to teaching evaluation because they do not focus on qualitative information about the course or teaching being evaluated. Rather, they may promote unnecessary competition and lack of collegiality and the answers to the questions are useless to the teacher. ${ }^{17}$ It should be stressed to students that the feedback must only concern itself with the teaching performance of the teacher seeking the feedback students should be discouraged from giving feedback about other teachers in the same (or any other) course.

Student evaluation can also be sought by meeting a group of students and asking them for their opinions on the course and its teaching. To be most effective, this needs to be done in a structured manner. One useful method involves giving students an opportunity to reflect on and make a note of the good and bad points of the course, the teaching, and the students. The students are then divided 
into groups of three or four to produce an agreed list of comments. Each group then contributes one good point about the course which is noted on the board or overhead projector and checked to see if the rest of the class agree. The process is repeated until all the categories have been discussed. ${ }^{18}$ Students can also be asked to suggest solutions to problems. This form of evaluation can be conducted by the teacher concerned, or by a member of an educational support unit. Involving students in this way often has the result of making students more responsible for preparing for class, attending and contributing in class.

There are other methods for checking student learning. Two possibilities are looking at student notes to see whether they are getting the main points and arguments raised in class; and near the end of a class to ask students to write down the three most important things that would best summarise the content of the class and compare it with the three points listed by the teacher. ${ }^{19}$

\section{Feedback from Colleagues}

A second method for evaluating teaching is through advice from, and observation by, trusted colleagues or educational experts. Colleagues can give good advice on the quality of the course itself - its value, academic credibility, comprehensiveness, assessment and the relevance of its content. ${ }^{20}$ The colleague should have the necessary expertise in the subject matter and should give rigorous, but constructive, criticism. ${ }^{21}$

Performance in the classroom can be observed by colleagues who then give constructive feedback to the teacher. This is the model adopted, very successfully I think, by the ALTA Law Teaching Workshop, but is largely ignored in law schools. The aim here is to give constructive feedback so that the teacher concerned is able to improve her or his teaching. The value of the feedback exercise depends to a large extent on the training and skill of the colleague giving the feedback. In a sense, the person giving the feedback becomes the coach of the teacher, but is involved principally in giving information about the teacher's performance and, above all, support. It is best to begin feedback by asking the teacher to carry out self evaluation. Comments during feedback should be descriptive of specific behaviour and should focus on the things that the teacher can change rather than on characteristics of 
the individual. The teacher should only be given as much feedback as she or he can handle. The teacher should listen carefully and resist making self justificatory statements. The whole purpose of the feedback is to provide information to improve teaching, not to make judgments about the teacher. The feedback should be given orally and in written form. Feedback from colleagues can also be sought about the quality of reading guides and printed materials and other aspects of teaching.

It is very important that this process be constructive and that there be mutual trust and support. The whole process is confidential as between the teacher and the colleague giving feedback. There is no point in engaging in this process if the feedback becomes part of the assessment of the teacher because this would inhibit the process and make the teacher unwilling to take chances and try out new methods, techniques and devices in the classroom. ${ }^{22}$ There is no reason, however, why law teachers should not be able to include in their teaching portfolios for the purposes of selection, confirmation or promotion an indication that they have participated in this feedback exercise in an effort to develop their teaching, provided that there is no pressure on them to disclose the comments made about their teaching during this process.

This method has a number of advantages, the most important being that it assists in the improvement of teaching by making all concerned focus on the criteria for good teaching and how to satisfy those criteria. The level of debate and experimentation about teaching is bound to improve. There are difficulties with feedback from colleagues, however. It is difficult for a colleague to make an accurate assessment of another's teaching by simply observing a few, probably unrepresentative classes, ${ }^{23}$ and an experienced colleague may also find it difficult to evaluate whether the teacher is explaining things well to a novice. It may be difficult for the colleague to comment on whether the teaching is enhancing learning. Unless the colleague giving the feedback can accept that there are different styles of teaching, her or his comments may simply reflect the fact that the teacher being evaluated does not have the same style of teaching as she or he does. One way of avoiding this problem is to provide the visiting colleague with a checklist of teaching characteristics which is to be the basis of the evaluation. 


\section{Analysis by Video}

A third method of feedback which can be used together with student assessment or feedback from colleagues is the videotaping of classes for the benefit of the teacher. Once again, this is a technique used very effectively by the ALTA Law Teaching Workshop. The best feedback about a teacher's teaching performance is undoubtedly the camera - the teacher is then able to study the video afterwards and find out what can be improved and what strengths should be developed.

It is very easy to produce a video of classroom teaching. All that is needed is a video camera, a tripod and a willing colleague. It goes without saying that the video is only for the eyes of the teacher.

Feedback in any of the forms discussed above is only useful if three conditions are satisfied. ${ }^{24}$ First, the teacher needs to get new information from the feedback but must not get more information than she or he can assimilate. Too much information can dazzle and confuse. This is particularly a problem with student evaluation forms unless care is taken to limit the information sought from students.

Secondly, a teacher will not benefit from the information obtained from the different forms of feedback unless the teacher is motivated to improve. One problem which often arises is that student feedback can have negative effects upon motivation because the teacher can feel that she or he is not liked by the class or is powerless to improve the course or teaching methods.

Thirdly, the teacher must be able to generate alternative ways of developing the course or different teaching methods.

\section{Self-Evaluation}

Self-evaluation of an individual staff member's teaching is also important to the process of evaluation. This involves reflection and review, based on a checklist for evaluation which aims to highlight different aspects of curriculum development and teaching. Such a list might ask for example:

- Are the aims of the course explicit? Is the content accurate and up to date?

- Are students being given an opportunity to develop relevant 
skills?

- Are the teaching methods appropriate, supporting the aims and objectives of the course?

- Are the assessment procedures valid?

- Are students given sufficient feedback about their performance?

- Do students believe that the teacher is accessible for assistance out of class?

- Is the course too demanding or not demanding enough? ${ }^{25}$

Most importantly, self-evaluation also involves correlating evidence from all the sources discussed so far in this section, setting future goals and making judgments about changing the course or the method of teaching. It is also important to monitor changes once they have been made. Is a new teaching method useful, or should it be abandoned or modified?

One way of linking information and action is to keep a course $\operatorname{logbook}^{26}$ which enables a record to be made of the course as it unfolds: the good things in the teaching of the course, any problems that have emerged and how they are to be resolved, evaluations that have been conducted and results of student work, particularly if these results suggest changes.

A crucial aspect of evaluating teaching for the purposes of selfimprovement is that there be a very supportive environment for teachers who have discovered and are trying to rectify weaknesses. In particular, teachers need to be encouraged to experiment and often need advice about different approaches to the course and the teaching method. Teachers who feel anxious about their teaching are least likely to change. Some law schools have set up teaching interest groups which could go some way to providing this environment, but they should not be the only means of providing support and advice in the area of teaching. Other methods of staff development and support need to be developed utilising colleagues from academic support and development units providing professional services to staff in most universities. These units can also provide advice and assistance in devising procedures for evaluation and in deciding how to improve teaching practices. ${ }^{27}$ Teachers requesting resources to attend courses on teaching should be strongly supported and encouraged. 


\section{ASSESSMENT OF TEACHING}

Equity and fairness suggest that there should be greater effort devoted to the assessment of teaching for the purposes of staff selection, confirmation and promotion. While all may notionally accept that teaching is important, in fact it is largely ignored for these purposes. When teaching is assessed it is largely by hearsay, rumour and innuendo. The rest of this article attempts to propose a tentative model to assess teaching performance.

There are at least three ways of assessing teaching for the purposes of selection, confirmation, or promotion, and all three have already been adverted to, albeit in different forms, earlier. As each source of information is susceptible to bias, poor reliability, or limited objectives, all the sources should be used and no assessment system should rely on only one source. The assessment of teaching should be separated from the use of feedback to improve teaching performance.

\section{Student Assessment}

If student assessment is to be used and the results aggregated for use in a teaching portfolio, this should be done separately from the process of regular feedback from students. Students should be told that the assessment forms are for the purposes of assessing teaching for a teaching portfolio. The assessment forms should be distributed and collected under specially prescribed conditions at particular times, not by the teacher concerned, but by an independent person. In addition, ratings should ideally be collected for several courses over a period of time for each member of staff before the results are attributed any real meaning. It is crucial that the assessment system be fair and be seen to be fair. ${ }^{28}$ Students should also be told to confine their comments to the teacher being assessed and should avoid gratuitous comments (good or bad) about other teachers in the same (or any other) course. There is room for scepticism about the fairness of relying on student assessment for the purposes of evaluating teaching. Teachers could be placed under a lot of pressure to give straight lectures and to spoon feed in order to improve their ratings. On the other hand, student assessment will force more time to be spent discussing with students the approach to teaching to be adopted, so that they are 
aware of the objectives of the course and the teaching methods utilised. This can only be of benefit to all concerned.

\section{Self-Assessment}

This method is of limited value because there is a natural tendency for teachers, understandably, to overrate their teaching performance. ${ }^{29}$ Nevertheless, this method does give teachers the opportunity to describe their teaching responsibilities and accomplishments. To be as useful as possible it should include illustrative materials and evidence of accomplishments, such as the objectives and syllabus of the course, the methods and materials used in instruction and assignments and examinations. ${ }^{30}$

\section{Peer Assessment}

Assessment by colleagues should be sensitively handled, because much could be at stake and because peer visitation without an adequate framework is a notoriously ineffective method of assessing teaching. ${ }^{31}$ In order to use peer visitation most effectively, care should be taken to ensure that the process is not arbitrary and it should be accompanied by other methods of assessment. It should involve more than one person conducting the assessment and each assessor should make at least three or four visits to the classes of the teacher being assessed. Peer visitation might follow this procedure.

- Before the assessment takes place clear criteria of good teaching need to be established. This will involve much discussion, thought and debate. A starting point is that the ultimate criterion for effective teaching is evidence of its impact upon student learning. There will also need to be judgments made about which goals are the most important — the instilling in students of a desire for learning and curiosity about the subject matter so that they try to learn; the acquisition by students of skills in thinking, writing, speaking; applying law to facts; synthesising material and so on; or comprehensive knowledge of the law. ${ }^{32}$ Another useful point of departure may be the University's criteria for teaching for the purposes of promotion. While it is unlikely that there will ever be total agreement about what constitutes good teaching, recent research has dispelled the myth 
that its elements are difficult to pinpoint. The process of debate about what constitutes good teaching is important and will provide a basis for the fourth step in this suggested process. ${ }^{33}$

- The persons doing the assessment should be trained in the assessment of teaching. Assessment of teaching is a difficult task and there is no guarantee that long experience as a teacher is enough to ensure competence. There will need to be agreement about the appropriate level of training.

- The persons doing the assessment should be trusted by the teacher being assessed. This is a complex issue involving trust on a personal level and respect for the teaching competence and approach to teaching of the persons who are assessing. It may be that the person being assessed should be given a list of potential assessors and be able to choose from the list the persons who should do the assessment. Alternatively, the teacher being assessed could nominate a list of people from which two people could be selected to carry out the assessment. There are limits to this process since it will be undermined if the relationship between the assessor and the teacher is such that the process is given lipservice.

- The assessors and the teacher should meet to discuss the criteria to be used prior to the assessment. The criteria must arise out of the debate in the first step of this process. Teachers have different styles, objectives and methods and it should be clear that the assessors are aware of the objectives, teaching philosophy and methods of the teacher being assessed.

- The assessors should also give the teacher a clear indication when the classroom assessment is to take place. Assessment by ambush should be avoided at all costs. In principle, assessment should not take place in a course that is being taught for the first time. The assessment of reading guides and materials can be conducted in a less formal manner, but should be an essential part of the assessment.

- The assessment should be in writing and there should be a separate assessment for each class observed. Standard assessment forms should be developed by each institution and the forms should relate to the criteria discussed in the first step of this process, permitting adaption to allow for the type of discussion envisaged in the fourth step. The assessment forms 
should aim at providing qualitative information and should avoid numerical or similar ratings. ${ }^{34}$

- The assessors and the teacher should meet as soon as possible after the assessment takes place. Each assessor should indicate her or his assessment of the classes, teaching method and teaching materials and, if necessary, should offer suggestions for improvement. If the teaching performance is not satisfactory, the teacher should be counselled and advised whether by the assessors or other colleagues. If necessary, the teacher should then be given another chance to teach in front of the original or another assessor.

All the sources of information for the assessment of teaching should then be collated and reviewed by those with responsibility for the assessment of teaching. The teacher should receive a copy of the final assessment and should be given an opportunity to respond to points raised in it. Consideration also ought to be given to an appellate process within the university and procedures to enable serious disputes and grievances to be resolved in a fair and equitable manner. It needs to be recognised that the assessment of teaching can give rise to serious industrial relations issues. Industrial relations procedures involving the relevant trade union must be in place to resolve these issues before they give rise to resentment and undermine staff morale.

Some will argue that this is a time consuming and laborious process. It probably is, but I contend that if teaching is to be assessed properly it must be done intelligently and fairly. The consequences flowing from the assessment of teaching are very serious - it could involve colleagues not having their tenure confirmed or being refused promotion — and assessment should, therefore, be done with care and rigour. There will be huge benefits from this process. It will involve staff and students alike, thinking about teaching and reassessing their own attitudes and approaches to teaching. This can only be a good thing.

\section{CONCLUSION}

For too long lipservice has been paid to university teaching. The times, however, are changing and there will inevitably be pressures not only for teaching to be improved in universities, ${ }^{35}$ but also for it to be properly assessed. If handled properly, this can be an 
extremely beneficial development. But no one should lose sight of the fact that the most important thing is for teaching to be improved and to that end, the focus of any process which scrutinises teaching should be on the evaluation of teaching. But evaluation is not an end in itself. Rather, it is always aimed at improving student learning. Each method of evaluation discussed above can only give a partial picture of teaching performance and consequently many methods of evaluation should be used. At the same time, fair and rigorous methods of assessing teaching need to be developed, along the lines perhaps of the procedure outlined.

* University of Melbourne Law School. Numerous people have commented on previous drafts on this article, and most of their suggestions have been adopted. In particular, I would like to thank Paul Ramsden, Hilary Charlesworth, Jenny Morgan, Annie McCrindle, Greg Craven, Ian Malkin, Michael Gommelin, Richard Ingleby, Mary Hiscock, and Sandy Clark for their comments and suggestions.

(C) 1990. (1990) 2 Legal Educ Rev 101.

1 See Australian Universities Academic Staff (Conditions of Employment) Award 1988.

2 The term "scrutinise" has been used here to cover all processes in which teaching is evaluated, appraised or assessed.

3 For a more thorough discussion of these distinctions, see P Ramsden \& A Dodds, Improving Teaching and Courses: A Guide to Evaluation (Melbourne: Centre for the Study of Higher Education, University of Melbourne, 1989) at 27.

Id at 2-3,57.

5 Id at 4 5; WJ McKeachie, The Role of Faculty Evaluation in Enhancing College Teaching (1983) 63 National Forum 37, at 39.

6 For a brief discussion of staff appraisal, see P Ramsden, Evaluating Teaching: Supporting Learning, in Higher Education Research and Development Society of Australasia, Papers Presented to the Annual Conference (Griffith University, 6-9 July 1990) at 4-7.

7 See J Morgan, The Socratic Method: Silencing Co-operation (1989) 1 Legal Educ Rev 151; TL Banks, Gender Bias in the Classroom (1988) 381 Legal Educ 137; CW Hantzis, Kingsfield and Kennedy: Reappraising the Male Models of Law School Teaching (1988) 381 Legal Educ 155; SM Wildman, The Question of Silence : Techniques to Ensure Full Class Participation (1988) 38 J Legal Educ 147.

8 JA Centra, The How and Why of Evaluating Teaching (1980) 71 Engineering Educ 205 [hereinafter Evaluating Teaching]; JA Centra, Self-Ratings of College Teachers: A Comparison with Student Ratings (1973) $10 \mathrm{~J}$ Educ Measurement 287.

9 McKeachie, supra note 5, at 37; Ramsden, supra note 6, at 1.

10 JA Centra, The Effectiveness of Student Feedback in Modifying College Instruction (1973) 65 J Educ Psych 395.

11 See generally, Ramsden supra note 6, at 1-2.

12 A Petter, A Closet Within the House: Learning Objectives and the Law School Curriculum, in N Gold ed, Essays in Legal Education (Toronto: Butterworths, 1982) 77; BS Bloom ed, Taxonomy of Educational Objectives: Handbook 1: 
Cognitive Domain (New York: Longman, 1956); G Krathwohl, Taxonomy of Educational Objectives: Handbook 2: Affective Domain (New York: Longman, 1956).

13 WH Bergquist \& SR Phillips, Handbook for Faculty Development (Washington: Council of Independent Colleges, 1975) vo1 1 ch 2; Hantzis, supra note 7.

14 G Gibbs, S Habeshaw \& T Habeshaw, 53 Interesting Things to do in Your Lectures (Bristol: Technical \& Educational Services Ltd, 1987).

15 Of course, as the next part of this article will argue, separate student assessment forms should be given to students at the end of the course.

16 For a useful discussion of student evaluation, see Ramsden \& Dodds, supra note 3 , at $16-28,42-46$.

17 Id at 34.

18 See G Gibbs, Eliciting Student Feedback From Structured Group Sessions (Oxford: Oxford Polytechnic Educational Methods Unit, 1982).

19 Gibbs, Habeshaw \& Habeshaw, supra note 14.

20 See McKeachie, supra note 5, at 38.

21 See Ramsden \& Dodds, supra note 3, at 10-13.

22 This is not to say that assessment of teaching by peer observation is not to be carried out for the purposes of confirmation, promotion or staff selection - this will be discussed in part three of this article. The important point, however, is that this must be a separate process.

23 McKeachie, supra note 5, at 38. Research suggests that peer observation has a low reliability: see JA Centra, Colleagues as Raters of Classroom Instruction (1975) 46 J Higher Educ 327.

24 McKeachie, supra note 5, at 38.

25 For examples of checklists, see Ramsden \& Dodds, supra note 3, at 11-12; D Rowntree, Developing Courses for Students (Maidenhead: McGraw-Hill, 1981); E Roe \& R McDonald, Informed Professional Judgment (St Lucia: University of Queensland Press, 1984).

26 See Rowntree, supra note 25.

27 Ramsden and Dodds argue that educational support units should not should focus on assisting teachers evaluate their courses, and should never be involved in staff appraisal and individual performance assessment activities. Ramsden \& Dodds, supra note 3.

28 See generally, Ramsden, supra note 6, at 9 .

29 See Evaluating Teaching, supra note 8, at 205.

30 Id at 205-06.

31 McKeachie, supra note 5, at 38.

32 Id at 37.

33 See below.

34 See the comments about student evaluation forms noted above.

35 See for example, Parliament of the Commonwealth of Australia, Senate Standing Committee on Employment, Education and Training, Priorities for Reform in Higher Education (Canberra: AGPS, 1990) especially chs 1-3, and all the references to teaching in the report. 